\title{
Intraspecific variation in the olfactory response of the predatory mite Neoseiulus womersleyi Schicha (Acari: Phytoseiidae) to different amount of spider mite-infested plant volatiles
}

\author{
Taro MAEDA ${ }^{1, *}$ and Yining LIU ${ }^{2}$ \\ ${ }^{1}$ Natural Enemies Laboratory, Insect Genetics and Evolution Department, National Institute of Agrobiological Sciences; Tsukuba \\ 305-8634, Japan \\ ${ }^{2}$ School of Life Science, East China Normal University; Shanghai 200062, China
}

(Received 20 April 2005; Accepted 29 November 2005)

\begin{abstract}
We investigated the olfactory responses of six strains of the predatory mite Neoseiulus womersleyi Shicha to different amounts of volatiles of Tetranychus urticae Koch-infested kidney bean plants. Four strains of the predators were collected from different sites in Japan (i.e., 4 geographical populations). The other two strains were inbred lines bidirectionally selected from a base population for their olfactory responses. All strains showed significantly higher olfactory preferences for the volatiles of 15 plants than those for 5 plants. We found a significant correlation between preferences for 15 plants and those for 5 plants. The olfactory preferences for spider mite-infested plant volatiles differed significantly among strains. The olfactory preferences of the 2 inbred strains were significantly different. These results suggest that the variation among local populations may result from genetic differences in sensitivity to spider miteinduced plant volatiles.
\end{abstract}

Key words: Neoseiulus womersleyi; inter-population variation; Tetranychus urticae; olfactory response; selection

\section{INTRODUCTION}

Several predatory mite species are known to be attracted to the volatiles emitted from plants infested with spider mites (e.g., Sabelis and van de Baan, 1983; Dicke et al., 1989, 1990a, b; Janssen et al., 1990; Bruin et al., 1992; Koveos et al., 1995; Takabayashi et al., 1995; Krips et al., 1999; Maeda et al., 1999). The volatiles emitted from these preyinfested plants are detectable cues to predatory mites as a result of their volatile nature, and they reliably indicate the presence of prey on the plant (reliability and detectability problems: for reviews, see Vet and Dicke, 1992; Dicke, 1994, 1999).

The volatiles produced by plants infested with spider mites are quantitatively and qualitatively affected by several factors such as plant species (Dicke and Sabelis, 1988; Van Den Boom et al., 2004); plant developmental stage (Takabayashi et al., 1994, 1995); spider mite species (Sabelis and van de Baan, 1983; Takabayashi et al., 1991); and density of spider mites (Maeda and Takabayashi, 2001). Since several predatory mites prey on more than one spider mite species (Overmeer, 1985; Hamamura, 1986), and spider mites are highly polyphagous (Jeppson et al., 1975), predatory mites survive on various plant-prey combinations. This means that the different local populations might have encountered qualitatively and quantitatively different volatiles. As natural selection would favor the predator genotypes that are best able to use information related to their prey (Price et al., 1980; Dicke and Sabelis, 1988), different local populations may have experienced differential natural selection for their olfactory response.

Inter-population genetic variation in the olfactory response was investigated with the predatory mite Neoseiulus womersleyi Shicha (Acari: Phytoseiidae) (Maeda et al., 2001; Maeda, 2005). N. womersleyi (equal to Amblyseius womersleyi in our previous studies, see Ehara and Amano, 2004) is a predatory mite that prefers spider mites of the

* To whom correspondence should be addressed at: E-mail: tarom@affrc.go.jp DOI: $10.1303 / \mathrm{aez} .2006 .209$ 
genus Tetranychus. Some geographical populations of $N$. womersleyi showed no preference for a given amount of volatiles of spider mite-infested kidney bean plant leaves (Maeda, 2005). Here, a question arises: whether the populations showing no preference can respond to larger amounts of volatiles or not. Detailed investigation of the olfactory response to quantitatively and qualitatively different blends of plant volatiles would provide important insights into the selection pressures that shape the intraspecific variation in olfactory responses. In the present study we focused on the variation in the olfactory responses of $N$. womersleyi to quantitatively different volatiles. In addition, to clarify whether the olfactory response of $N$. womersleyi to quantitatively different volatiles has a genetic basis or not, we used inbred lines of $N$. womersleyi selected for their olfactory responses as well as several geographical populations.

\section{MATERIALS AND METHODS}

Plants. We used kidney bean plants, Phaseolus vulgaris L., as a food source for T. urticae and as odor sources for bioassays. The plants were reared in plastic pots (10-cm diameter, 11-cm depth) filled with vermiculite in a climate-controlled room $\left(19 \pm 1^{\circ} \mathrm{C}, 50 \%\right.$ to $70 \%$ R.H., $16 \mathrm{~L}: 8 \mathrm{D}$ photoperiod; ca. $4,0001 \mathrm{x})$. When the two primary leaves had fully unfolded, which occurred about 2 to 3 weeks after germination, the plants were used for the experiments.

Herbivorous mites. T. urticae had been maintained on kidney bean plants in the laboratory for more than $2 \mathrm{y}$ at $25 \pm 2^{\circ} \mathrm{C}, 60 \%$ to $80 \%$ R.H., and $16 \mathrm{~L}: 8 \mathrm{D}$ conditions. We offered about 70 plants to the spider mites every 10 to $14 \mathrm{~d}$.

Predatory mites. $N$. womersleyi were collected at four different sites in Japan (Table 1). These populations were chosen based on the olfactory responses in the previous study (Maeda, 2005). The populations were maintained separately on an acrylic resin plate and were offered five primary leaves of kidney bean plants infested with $T$. urticae three times per week (for details, see Maeda, 2005).

Bidirectional selection. To develop two inbred lines that show high and low olfactory responses to T. urticae-infested plant volatiles, bidirectional selection was conducted. As the number of collected individuals of MKK population (Table 1) was the largest among the populations used in the present study, it was expected that the MKK population had the largest genetic diversity. Therefore, the MKK population was used as the base population for the selection. The olfactory responses of the $N$. womersleyi were examined using a Y-tube olfactometer (Takabayashi and Dicke, 1992). To prepare a homogeneous sample odor source, we introduced 30 adult female $T$. urticae onto each primary leaf of 5 bean plants, and then reared the plant and mites in a climate-controlled incubator $\left(20 \pm 1^{\circ} \mathrm{C}\right.$; $70 \pm 5 \%$ R.H.; $16 \mathrm{~L}$ : 8D; ca. $10,0001 \mathrm{x}$ ) for 2 weeks. Intact plants grown under the same conditions were used as the control odor source. Gravid females of $N$. womersleyi were randomly picked from the stock culture and introduced individually at the starting point (i.e., the downwind end) of a Yshaped iron wire in the center of the olfactometer. The olfactory responses of adult females of $N$. womersleyi were observed for $5 \mathrm{~min}$. When the predator did not make a choice within $5 \mathrm{~min}$, this behavior was classified as "no choice."

The predators that made a final choice were kept on bean leaflets that were heavily infested with $T$. urticae. The choice tests were repeated three times per individual. Predator females that chose T. urticae-infested plant volatiles three times were designated as the high response line ("MKK-H") and sent to the next selection procedure. Females that chose intact plant volatiles three times were designated as the low response line ("MKK-L"). The two lines were kept separately and their offspring were subjected to the next selection procedure. This procedure was repeated for 5 generations.

Olfactory response to different amounts of volatiles from $T$. urticae-infested plants. To test the effects of the amount of volatiles from $T$. urticae-infested plants on the olfactory response of the predatory mites, we used two sets of odor sources: 5 infested plants and 15 infested plants. The same numbers of intact plants were used as the control odor source. Olfactory preferences were expressed as the percentage of mites that chose the spider-mite infested plants volatiles. No-choice individuals were excluded from the analysis.

Chemical analysis of volatiles emitted from whole plants and detached leaves. To identify the volatiles emitted from T. urticae-infested kidney bean plants, headspace volatiles were analyzed 
by GC-MS. We placed five odor source plants (infested or uninfested) in an acrylic resin box $(20 \times 30 \times 50 \mathrm{~cm})$. We pre-cleaned the air $(200 \mathrm{ml} / \mathrm{min})$ through three $500-\mathrm{ml}$ glass bottles filled with activated charcoal, granular silica gel, and 3A molecular sieve (Wako Pure Chemical Industries, Ltd., Osaka, Japan) respectively. The clean air was sent to the odor source boxes, and finally through a tube filled with absorbent material (Gerstel 1377, Tenax TA, Mülheim, Germany) for $1 \mathrm{~h}$. We analyzed the collected volatiles using a GC-MS [GC (Agilent GC6890 with an HP-5MS capillary column: $30 \mathrm{~m}$ long, $0.25 \mathrm{~mm}$ in diameter, $0.25-\mu \mathrm{m}$ film thickness) with a thermal desorption system (TDS; TDS2, Gerstel) packed with a cool injection system (CIS4, Gerstel); MS (Agilent 5973 mass selective detector, $70 \mathrm{eV})]$. The TDS temperature was programmed to rise from $30^{\circ} \mathrm{C}(1$ min hold) to $280^{\circ} \mathrm{C}$ (4-min hold) at $60^{\circ} \mathrm{C} / \mathrm{min}$. The CIS temperature was programmed to rise from $-100^{\circ} \mathrm{C}\left(0.5\right.$-min hold) to $300^{\circ} \mathrm{C}(5$-min hold) at $12^{\circ} \mathrm{C} / \mathrm{s}$. The oven temperature of the GC6890 was programmed to rise from $50^{\circ} \mathrm{C}$ (9-min hold) to $280^{\circ} \mathrm{C}$ at $15^{\circ} \mathrm{C} / \mathrm{min}$. We compared the spectra of the compounds isolated with those in a mass spectra database (Wiley 7th edition) and with existing mass spectra data for previously identified herbivore-induced volatiles in our laboratory to infer the chemical structure of each of the compounds. In the present study, we regarded any volatile compounds whose amount was significantly larger ( $t$ test) in the headspace of the infested plants than in that of uninfested plants as T. urticae-induced volatiles.

Olfactory response to methyl salicylate. We tested the olfactory responses of the predatory mites to methyl salicylate (Wako Pure Chemical Industries, Ltd.). Methyl salicylate was a commercially available chemical among the volatiles emitted from the spider mite-infested kidney bean plant (Maeda et al., 1998). Methyl salicylate was dissolved in hexane $(0.02 \mu \mathrm{g}, 0.2 \mu \mathrm{g}, 2 \mu \mathrm{g} / 1 \mu \mathrm{l}$ hexane solution). The diluted chemicals $(20 \mu \mathrm{l})$ were filled in a glass microcapillary $(25 \mu \mathrm{l}$, inner diameter $1 \mathrm{~mm}$, Microcaps; Drummond Scientific Company, US). The amount of methyl salicylate emitted from the $0.2 \mu \mathrm{g} / 1 \mu \mathrm{l}$ hexane solution was at an emission level similar to that made by 5 kidney bean plants infested with T. urticae. As a control odor source, $20 \mu \mathrm{l}$ hexane were used. We confirmed that hexane emitted from the microcapillary did not affect the olfactory response of the predatory mites. Nochoice individuals were excluded from the analysis.

\section{RESULTS AND DISCUSSION}

The kidney bean plants infested with $T$. urticae emitted significantly larger amounts of $(E)$-4,8-dimethyl-1,3,7-nonatriene (DMNT), methyl salicylate, and $(E, E)-4,8,12$-trimethyl-1,3,7,11-tridecatetraene (TMTT) than uninfested plants $(p<0.05, t$ test) (Fig. 1). The composition of the volatiles that we detected in the present study differed from that in a previous study (Maeda et al., 1998). However, in the previous study, we used detached leaves rather than entire potted plants. In a system of $T$. urticae and lima bean plants (P. lunatus L. cv. Sieva), Arimura et al. (2001) reported differences in the blend of volatiles between infested potted plants and infested detached leaves. Thus, it is likely that we did not detect some of the previously

Intact plants

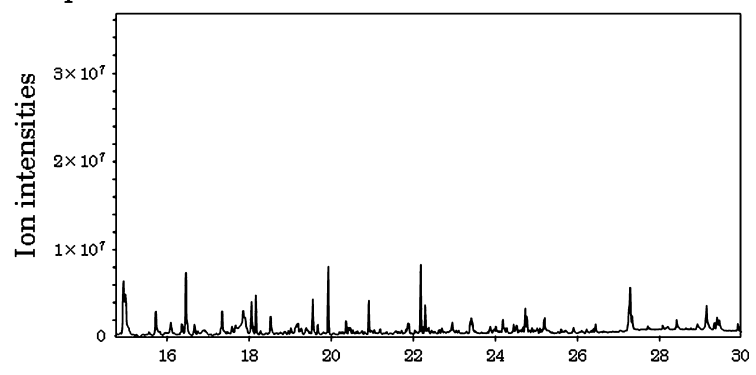

T. urticae-infested plants

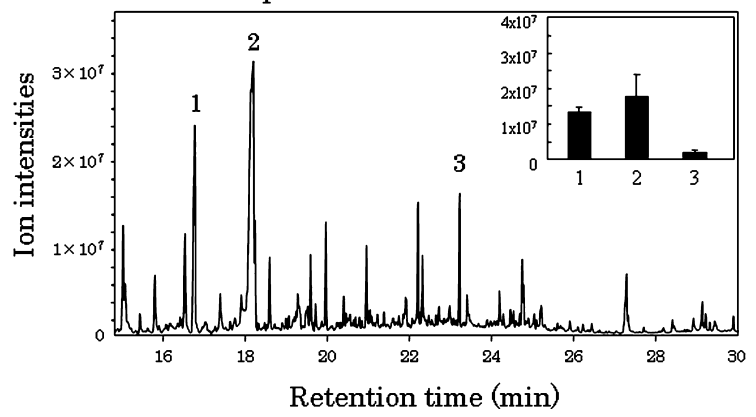

Fig. 1. Gas chromatograms of the volatiles emitted by intact kidney bean plants and T. urticae-infested kidney bean plants. Headspace volatiles were subjected to GC-MS analysis. Numbers next to peaks represent the volatile compound: 1, (E)-4,8-dimethyl-1,3,7-nonatriene (DMNT); 2, methyl salicylate; 3, (E,E)-4,8,12-trimethyl-1,3,7,11-tridecatetraene (TMTT). The amount (average peak area \pm S.E.) of these 3 compounds were shown in the small window. 


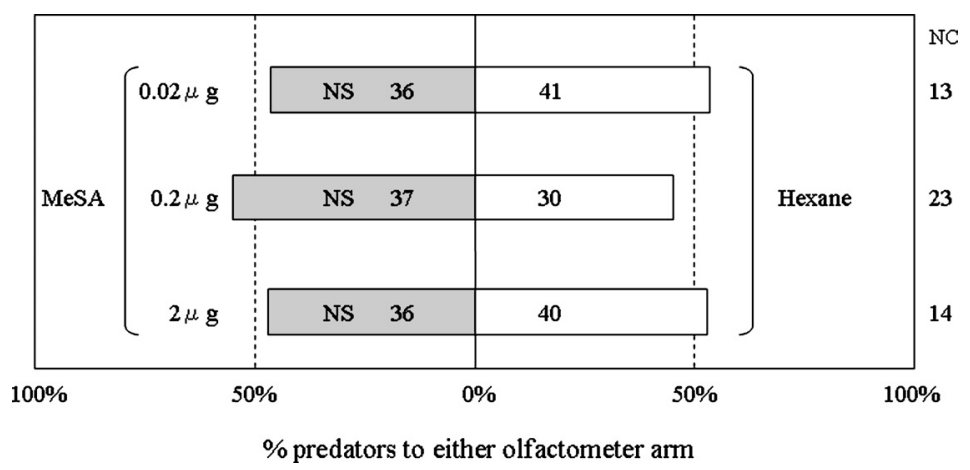

Fig. 2. Responses of $N$. womersleyi in a Y-tube olfactometer when offered different doses of methyl salicylate $(0.02 \mu \mathrm{g}, 0.2 \mu \mathrm{g}$, $2 \mu \mathrm{g} / 1 \mu \mathrm{l}$ hexane solution). As control odor source, hexane was offered. The number of predators that chose either the methyl salicylate or the control odor is shown in each bar. The number of individuals that made no choice (NC) is indicated on the right of the graph. The two-tailed binomial test was conducted to test whether the predators' choice between two odor sources was significantly different from an equal distribution (NS, not significant).

Table 1. Olfactory preferences and sampling records for 6 strains (4 geographical populations and 2 inbred lines) of N. womersleyi

\begin{tabular}{|c|c|c|c|c|c|}
\hline \multirow{2}{*}{ Strains } & \multicolumn{2}{|c|}{ Preference for volatiles $\%(n)$} & \multirow{2}{*}{ Sampling site } & \multirow{2}{*}{ Host plant } & \multirow{2}{*}{ Sampling date } \\
\hline & 5 plants & 15 plants & & & \\
\hline AZK & (104) & $61.6^{*} \quad(86)$ & Tsukuba, Ibaraki & Kudzu vine (Pueraria lobata) & Sept. 2002 \\
\hline HMK & $63.0^{*} \quad(92)$ & $73.2 * * *(71)$ & Hamaoka, Shizuoka & Kudzu vine $(P$. lobata $)$ & June 2003 \\
\hline KNT & $71.7 * * *(92)$ & $84.1 * * *(69)$ & Kanaya, Shizuoka & Tea (Camellia sinensis) & June 2003 \\
\hline MKK & $67.5^{* *}(77)$ & $75.0 * * *(72)$ & Mikuni, Fukui & Kudzu vine (P. lobata) & Sept. 2002 \\
\hline MKK-H & $70.1 * * *(107)$ & $76.3 * * *(80)$ & Mikuni, Fukui & & Sept. 2002 \\
\hline MKK-L & $58.7 \quad(109)$ & $63.1 * \quad(65)$ & Mikuni, Fukui & & Sept. 2002 \\
\hline
\end{tabular}

Statistical difference of olfactory preference from $50 \%$ was tested using the two-tailed binomial test $(* * * p<0.001 ; * * p<0.01$; $* p<0.05)$.

reported volatile compounds because of differences in the conditions of the plant materials between the two studies. DMNT is known to attract Phytoseiulus persimilis Athias-Henriot (Acari: Phytoseiidae) (Dicke et al., 1990a), and methyl salicylate attracts P. persimilis, N. californicus and Amblyseius potentillae Garman (Acari: Phytoseiidae) (Dicke et al., 1990a; Shimoda et al., 2005). Methyl salicylate is an important signal for $P$. persimilis to identify the presence of spider mites (De Boer and Dicke, 2004a, b, 2005; De Boer et al., 2004). However, in the present study, $N$. womersleyi showed no preference for methyl salicylate (Fig. 2). As for DMNT and TMTT, it remains an open question as whether these components attract $N$. womersleyi or not.

When we used 5 plants as the odor source, the preferences of 6 strains (4 geographical populations and 2 inbred lines) for T. urticae-induced plant volatiles ranged from $51.9 \%$ to $71.7 \%$ (Table
Table 2. Results of a logistic regression analysis to test the effects of strains, amount of volatiles, and their interaction on the olfactory responses of $N$. womersleyi

\begin{tabular}{lcrc}
\hline \multicolumn{1}{c}{ Source } & d.f. & Wald $\chi^{2}$ & $p$ \\
\hline Strains & 5 & 24.563 & 0.0002 \\
Number of plants & 1 & 8.450 & 0.0036 \\
$\quad($ amount of volatiles) & & & \\
Strains $\times$ number of plants & 5 & 1.241 & 0.9408 \\
\hline
\end{tabular}

1). In contrast, the preferences for 15 plants ranged from $61.6 \%$ to $84.1 \%$. A logistic regression analysis showed that the preferences of $N$. womersleyi were affected by both the strains of $N$. womersleyi and the number of plants used as odor sources (Table 2). When we plotted the olfactory preferences of each strain for 5 infested plants and for 15 infested plants, we found a significant positive correlation $\left(y=1.152 x-2.755, R^{2}=0.875, p=0.0062\right.$, 
where $y$ is arcsine square-root transformed preference for 15 plants and $x$ is that for 5 plants) (Fig. $3)$. The observed variation in the olfactory response among 6 strains of predatory mites involved differences in their sensitivity to the quantity of volatiles produced from the plants; i.e., predators with relatively low sensitivity, such as the AZK population, responded only to large amounts of volatiles, whereas predators with high sensitivity, such as the KNT population, were able to respond to small amounts. Predators that respond to smaller amounts of herbivore-induced plant volatiles are likely to be more efficient in locating prey than conspecifics that require larger amounts of volatiles, and thus should have a selective advantage (Rosen and Huffaker, 1983). Jia et al. (2002) proposed that the disadvantage of a weak olfactory response of $P$. persimilis may be offset by other characteristics, such as a high consumption rate or a high oviposition rate; conversely, a low consumption rate and low oviposition rate could be compensated for by a strong olfactory response. However, the life-history traits of $N$. womersleyi such as predation rates, fecundity, and developmental times did not correlate with the olfactory response (Maeda, 2005). Instead of life-history traits, we found that the dispersal tendency of $N$. womersleyi correlated with their olfactory response; the predatory mites that could discriminate the prey-infested plant volatiles from uninfested plant volatiles tended to leave a prey patch sooner than the other predatory mites that did not discriminate between these plant volatiles (Maeda, 2005). These differences in behavioral traits may imply the presence of range of foraging strategies. The present study showed that the predatory mites that showed no preference for small amount of volatiles could respond to larger amount of volatiles. To discuss the difference of the foraging strategies among populations, further investigation about how much volatiles were emitted from the host plants in their foraging sites would be needed.

Genetic variation in some components of foraging behavior has been suggested in predatory arthropods and parasitoids (Hoy, 1990; Hopper et al., 1993). However, in tritrophic systems there is little evidence of a genetic component in the foraging behavior of predatory mite (however, see Margolies et al., 1997; Jia et al., 2002). In the present study, the selection experiment showed that $N$.

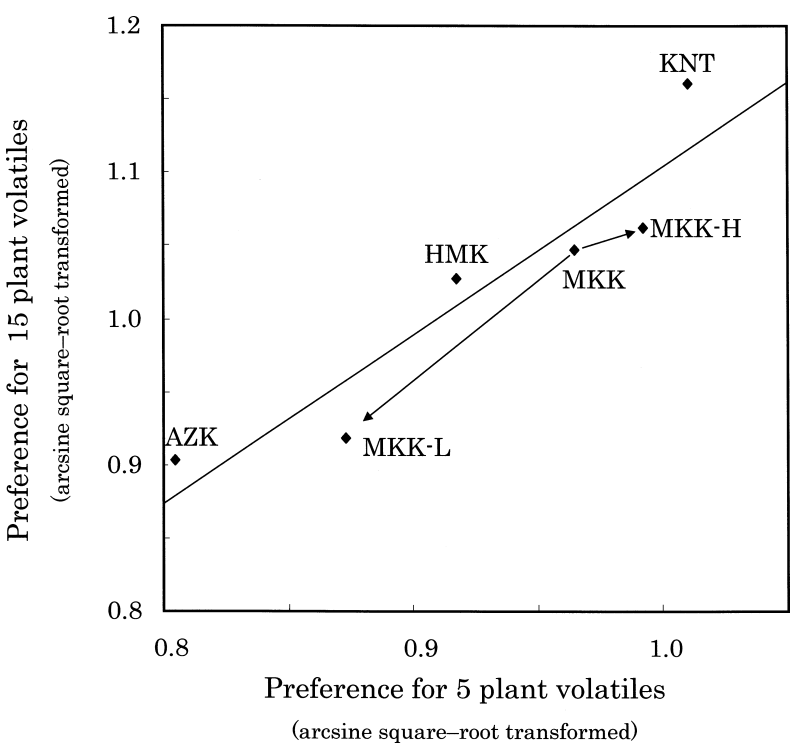

Fig. 3. Correlation between the olfactory responses to the volatiles from 5 plants and those from 15 plants. Simple regression analysis with arcsine-square root transformed data revealed a significant correlation $\left(y=1.152 x-2.755, R^{2}=0.875\right.$, $p=0.0062$ ).

womersleyi could be selected for olfactory response. After 5 generations of selection, the MKK$\mathrm{H}$ strain showed significant preference for the volatiles of both 5 and 15 plants $(p<0.001$, twotailed binomial test). On the other hand, the MKK$\mathrm{L}$ strain showed no preference for the volatiles of 5 plants ( $p>0.05$, two-tailed binomial test) and a slight preference for 15 plant volatiles $(p<0.05$, two-tailed binomial test). The preference of the MKK-L line was significantly lower than that of the MKK-H strain $(p<0.05$, logistic regression analysis). The selection response we observed in the present study (i.e., the arrows shown in Fig. 3) are likely to be additive evidence of genetic variation in predatory mite response to spider miteinduced plant volatiles.

\section{ACKNOWLEDGEMENTS}

We thank Dr. J. Takabayashi, Dr. N. Hinomoto, and Dr. T. Noda for their critical review of an early draft of this paper. This work was supported by the Program for Young Researchers with Fixed-term Appointments, Special Coordination Funds for Promoting Science and Technology, MEXT, Japan.

\section{REFERENCES}

Arimura, G., R. Ozawa, J. Horiuchi, T. Nishioka and J. Takabayashi (2001) Plant-plant interactions mediated by volatiles emitted from plants infested by spider mites. 
Biochem. Syst. Ecol. 29: 1049-1061.

Bruin, J., M. Dicke and M. W. Sabelis (1992) Plants are better protected against spider-mites after exposure to volatiles from infested conspecifics. Experientia 48: 525-529.

De Boer, J. G. and M. Dicke (2004a) Experience with methyl salicylate affects behavioural responses of a predatory mite to blends of herbivore-induced plant volatiles. Entomol. Exp. Appl. 110: 181-189.

De Boer, J. G. and M. Dicke (2004b) The role of methyl salicylate in prey searching behavior of the predatory mite Phytoseiulus persimilis. J. Chem. Ecol. 30: 255-271.

De Boer, J. G. and M. Dicke (2005) Information use by predatory mite Phytoseiulus persimilis (Acari: Phytoseiidae), a specialised natural enemy of herbivorous spider mites. Appl. Entomol. Zool. 40: 1-12.

De Boer, J. G., M. A. Posthumus and M. Dicke (2004) Identification of volatiles that are used in discrimination between plants infested with prey or non-prey herbivores by a predatory mite. J. Chem. Ecol. 30: 2215-2230.

Dicke, M. (1994) Local and systemic production of volatile herbivore-induced terpenoids: Their role in plant-carnivore mutualism. J. Plant Physiol. 143: 465-472.

Dicke, M. (1999) Are herbivore-induced plant volatiles reliable indicators of herbivore identity to foraging carnivorous arthropods? Entomol. Exp. Appl.91: 131-142.

Dicke, M., M. Jong, M. P. T. Alers, F. C. T. Stelder, R. Wunderink and J. Post (1989) Quality control of mass-reared arthropods: nutritional effects on performance of predatory mites. J. Appl. Entomol. 108: 462-475.

Dicke, M. and M. W. Sabelis (1988) How do plants obtain predatory mites as bodyguards? Neth. J. Zool. 38: $148-165$.

Dicke, M., T. A. van Beek, M. A. Posthumus, N. B. Dom, H. van Bokhoven and A. de Groot (1990a) Isolation and identification of volatile kairomone that affects acarine predator-prey interaction: Involvement of host plant in its production. J. Chem. Ecol. 16: 381-396.

Dicke, M., K. J. van der Maas, J. Takabayashi and L. E. M. Vet (1990b) Learning affects response to volatile allelochemicals by predatory mites. Proc. Exp. Appl. Entomol. 1: 31-36.

Ehara, S. and H. Amano (2004) Checklist and keys to Japanese Amblyseiinae (Acari: Gamasina: Phytoseiidae). J. Acarol. Soc. Jpn. 13: 1-30.

Hamamura, T. (1986) Studies on the biological control of kanzawa spider mite, Tetranychus kanzawai Kishida, by the chemical resistant predacious mite, Amblyseius longispinosus (Evans) in tea fields (Acarina: Tetranychidae, Phytoseiidae). Bull. Tea Res. Stn. 21: 122-197.

Hopper, K. R., R. T. Roush and W. Powell (1993) Management of genetics of biological-control introductions. Annu. Rev. Entomol. 38: 27-51.

Hoy, M. A. (1990) Commentary: The importance of biological control in U.S. agriculture. J. Sustain. Agric. 1: 59-79.

Janssen, A., C. D. Hofker, A. R. Braun, N. Mesa, M. W. Sabelis and A. C. Bellotti (1990) Preselecting predatory mites for biological control: The use of an olfactometer.
Bull. Entomol. Res. 80: 177-182.

Jeppson, L. R., H. H. Keifer and E. W. Baker (1975) Mites Injurious to Economic Plants. University of California Press, Berkeley. 614 pp.

Jia, F., D. C. Margolies, J. E. Boyer and R. E. Charlton (2002) Genetic variation in foraging traits among inbred lines of a predatory mite. Heredity 89: 371-379.

Koveos, D. S., N. A. Kouloussis and G. D. Broufas (1995) Olfactory responses of the predatory mite Amblyseius andersoni Chant (Acari, Phytoseiidae) to bean plants infested by the spider mite Tetranychus urticae Koch (Acari, Tetranychidae). J. Appl. Entomol. 119: 615-619.

Krips, O. E., P. E. L. Willems, R. Gols, M. A. Posthumus and M. Dicke (1999) The response of Phytoseiulus persimilis to spider mite-induced volatiles from gerbera: Influence of starvation and experience. J. Chem. Ecol. 25: 2623-2641.

Maeda, T. (2005) Correlation between olfactory responses, dispersal tendencies, and life-history traits of the predatory mite Neoseiulus womersleyi (Acari: Phytoseiidae) of eight local populations. Exp. Appl. Acarol. 37: 67-82.

Maeda, T. and J. Takabayashi (2001) Production of herbivore-induced plant volatiles and their attractiveness to Phytoseiulus persimilis (Acari: Phytoseiidae) with the change of Tetranychus urticae (Acari: Tetranychidae) density on a plant. Appl. Entomol. Zool. 36: 47-52.

Maeda, T., J. Takabayashi, S. Yano and A. Takafuji (1998) Factors affecting the resident time of the predatory mite Phytoseiulus persimilis (Acari: Phytoseiidae) in a prey patch. Appl. Entomol. Zool. 33: 573-576.

Maeda, T., J. Takabayashi, S. Yano and A. Takafuji (1999) Response of the predatory mite, Amblyseius womersleyi (Acari: Phytoseiidae), toward herbivore-induced plant volatiles: variation in response between two local populations. Appl. Entomol. Zool. 34: 449-454.

Maeda, T., J. Takabayashi, S. Yano and A. Takafuji (2001) Variation in the olfactory response of 13 populations of the predatory mite Amblyseius womersleyi to Tetranychus urticae-infested plant volatiles (Acari: Phytoseiidae, Tetranychidae). Exp. Appl. Acarol. 25: 55-64.

Margolies, D. C., M. W. Sabelis and J. E. J. Boyer (1997) Response of a phytoseiid predator to herbivore-induced plant volatiles: selection on attraction and effect on prey exploitation. J. Insect Behav. 10: 695-709.

Overmeer, W. P. J. (1985) Alternative prey and other food resources. In Spider Mites: Their Biology, Natural Enemies and Control. Vol. 1B (W. Helle and M. W. Sabelis eds.). Elsevier, Amsterdam, pp. 131-139.

Price, P. W., C. E. Bouton, P. Gross, B. A. McPheron, J. N. Thompson and A. E. Weis (1980) Interactions among three trophic levels: Influence of plants on interactions between insect herbivores and natural enemies. Аnnu. Rev. Ecol. Syst. 11: 41-65.

Rosen, D. and C. B. Huffaker (1983) An overview of desired attributes of effective biological control agents, with particular emphasis on mites. In Biological Control of Pests by Mites (M. A. Hoy, G. L. Cunningham and L. Knutson eds.). University of California Press, Berkeley, pp. $2-11$. 
Sabelis, M. W. and H. E. van de Baan (1983) Location of distant spider mite colonies by phytoseiid predators: Demonstration of specific kairomones emitted by Tetranychus urticae and Panonychus ulmi. Entomol. Exp. Appl. 33: 303-314.

Shimoda, T., R. Ozawa, K. Sano, E. Yano and J. Takabayashi (2005) The involvement of volatile infochemicals from spider mites and from food-plants in prey location of the generalist predatory mite Neoseiulus californicus. J. Chem. Ecol. 31: 2019-2032.

Takabayashi, J. and M. Dicke (1992) Response of predatory mites with different rearing histories to volatiles of uninfested plants. Entomol. Exp. Appl. 64: 187-193.

Takabayashi, J., M. Dicke and M. A. Posthumus (1991) Variation in composition of predator-attracting allelochemicals emitted by herbivore-infested plants: relative influence of plant and herbivore. Chemoecology 2: 1-6.
Takabayashi, J., M. Dicke, S. Takahashi, M. A. Posthumus and T. A. van Beek (1994) Leaf age affects composition of herbivore-induced synomones and attraction of predatory mites. J. Chem. Ecol. 20: 373-386.

Takabayashi, J., S. Takahashi, M. Dicke and M. A. Posthumus (1995) Developmental stage of the herbivore Pseudaletia separata affects production of herbivore-induced synomone by corn plants. J. Chem. Ecol. 21: 273-278.

Van Den Boom, C. E., T. A. Van Beek, M. A. Posthumus, A. De Groot and M. Dicke (2004) Qualitative and quantitative variation among volatile profiles induced by Tetranychus urticae feeding on plants from various families. J. Chem. Ecol. 30: 69-89.

Vet, L. E. M. and M. Dicke (1992) Ecology of infochemical use by natural enemies in a tritrophic context. Annu. Rev. Entomol. 37: 141-172. 